\section{Amino acids in clinical studies}

\section{A. Darbre}

Amino Acid Analysis. Edited by J.M. Rattenbury. Pp.380. ISBN UK 0-85312194-X; ISBN US 0-470-27141-8. (Ellis Horwood/Halsted: 1981.) $£ 27.50, \$ 89.95$.

WITH the appearance of the automated ion exchange column method of Spackman, Stein and Moore in 1958, amino acid analysis became one of the most important analytical techniques in biochemistry. Since that date there has been much research effort put into obtaining both faster and more sensitive analyses, and this has enabled the study of proteins, peptides and amino acids to be extended into many fields.

Proteins having unusual properties (e.g. anti-freeze protein) or specialized functions (e.g. receptor proteins on cell membranes) are being continually discovered and isolated, as are peptides and non-protein amino acids with important physiological and pharmacological properties.

This volume consists mainly of the papers given at a symposium, "Amino Acid Analysis in Clinical Chemistry and Medical Research", held in Edinburgh in June 1979. Thus the short title of the book is misleading - this is not a book for the reader whose primary interest is in protein

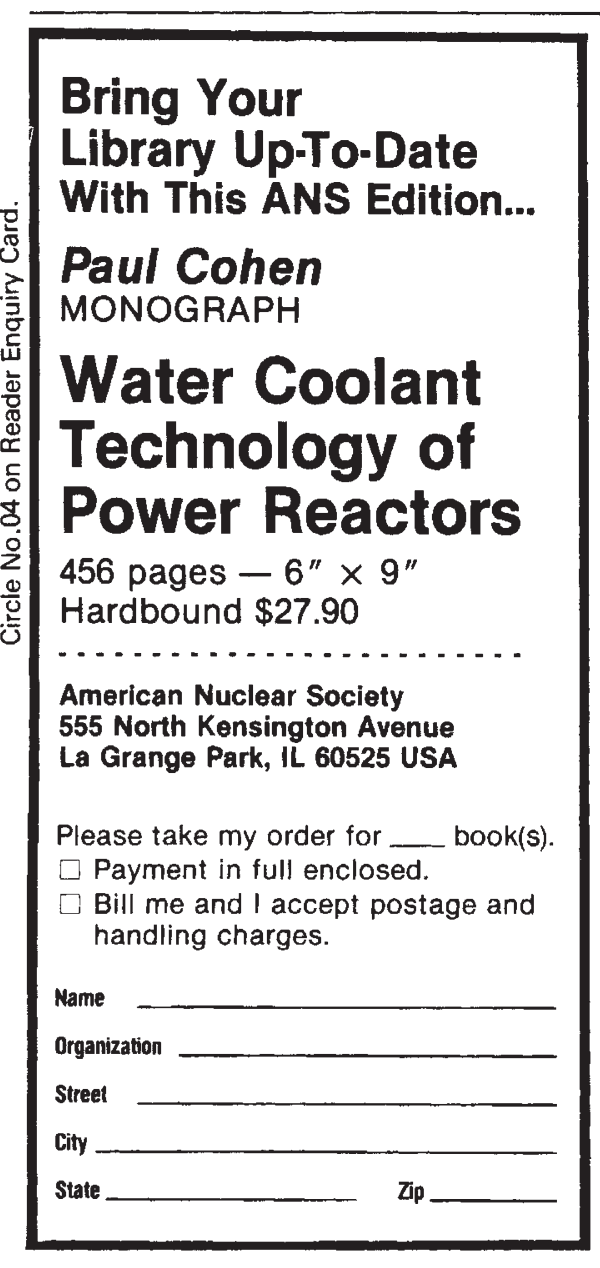

analysis or in methodology. The volume consists of 24 chapters and is divided into four parts. The first, on technical developments, contains 9 chapters which deal with analysis per se and review briefly the history of amino acid analysis, fluorimetric detection techniques, gas chromatographic methods, mass spectrometry, derivative spectroscopy and chemiluminescent nitrogen analysis. (The brief contribution on phenylthiohydantoin amino acids, however, does not have a logical place in this book.) The reader who may have accepted at face value widely disseminated statements that "today, it is possible to analyse picomole levels of amino acids in protein hydrolysates in $1 \mathrm{~h}$ with the automatic loading of up to 80 samples" (p.138), with complete computation and print out of the results to an accuracy of 3 per cent (see p.132), should read the chapters on standards and accuracy (R. P. Ambler) and collaborative trials (A. P. Williams). These should induce in the researcher a much more critical approach to the "print-out" of results obtained from the computing integrator!

The raison d'être for this volume lies in the last 15 chapters, which have been divided into separate parts under the headings of amino acid analysis in, respectively, physiological processes, systemic disease and congenital disorders. There is much of interest here, presented in easily readable form, but the emphasis is on results obtained in a physiological and clinical context, and not on the methods used. Thus there are chapters related to protein digestion and absorption (our knowledge here is still very inadequate), the effect of protein quality on plasma amino acid levels in low birthweight babies and plasma amino acids following parenteral nutrition of the newborn, and in chronic renal failure, acute liver failure and alcoholism. The specific analysis of 3-methylhistidine and hydroxyproline as a measure of protein breakdown, and amino acids as neurotransmitters are also discussed. Two contributions give generalized accounts of amino acid analysis in the study of inborn errors of metabolism, whilst others are devoted to homocystinuria, Wilson's disease and spina bifida.

All chapters include adequate references for further reading. But it should be noted that a new word - "exteriorisable" (p.153) has crept into the English language: this inborn error of grammar should be quickly eliminated.

A. Darbre is Senior Lecturer in Biochemistry at King's College, University of London.

\title{
Synmetals: a new branch to polymerization
}

\section{Herman Mark}

Semiconducting Polymers. By Marian Kryszewski. Pp.710. ISBN 83-01-00818-0. (Polish Scientific Publishers, Warsaw: 1981.) $\$ 35$.

FOR many years synthetic organic polymers have been of considerable interest and value for their mechanical and thermal properties such as rigidity, strength, elasticity, high softening range and chemical stability. With these properties they have been very useful in a variety of industries, textiles, films, sheets and plastics, for example. Several years ago, however, these materials underwent a surprisingly rapid development as "synmetals", that is, systems which can act as conductors or semiconductors. Their preparation and tailoring for the second application has now grown into a science and technology of considerable proportions.

Marian Kryszewski's Semiconducting Polymers is the first comprehensive treatment of this new field. It serves a twofold purpose: first, it familiarizes the reader briefly with the basic principles of semiconduction, and then it describes how this intriguing property can be obtained with organic polymers.
There are two principles which serve to establish semiconductivity in such systems: the presence of polyconjugated chains and the availability of charge transfer complexes. The largest part of the book is reasonably devoted to the description of polyacetylene because this has been more closely investigated and has already led to semiconductors of wide potential application - f.i. in the construction of new types of photovoltaic cells, pacemakers and thin electrical batteries. Also included in the account of their preparation and behaviour are descriptions of their photoconductivity, magnetic characeristics and catalytic activity.

The author has been through his topic with great assiduity and diligence. For the generally interested reader he has provided a lucid and attractive story; the expert, too, will be grateful to him for the 3,000 or so references which constitute a comprehensive bibliography.

This is a remarkable book and, as the new field grows and unfolds, it may well one day be seen as a classic.

Herman Mark is Dean Emeritus of the Polytechnic Institute of New York. 